Portland State University

PDXScholar

$5-24-2017$

\title{
Culturally Responsive Diabetes Interventions within the Context of American Indian and Alaska Native
} Health

Leilani J. Freeman

Portland State University

Follow this and additional works at: https://pdxscholar.library.pdx.edu/honorstheses Let us know how access to this document benefits you.

\section{Recommended Citation}

Freeman, Leilani J., "Culturally Responsive Diabetes Interventions within the Context of American Indian and Alaska Native Health" (2017). University Honors Theses. Paper 393.

https://doi.org/10.15760/honors.389

This Thesis is brought to you for free and open access. It has been accepted for inclusion in University Honors Theses by an authorized administrator of PDXScholar. Please contact us if we can make this document more accessible: pdxscholar@pdx.edu. 
Running Head: CULTURALLY RESPONSIVE DIABETES INTERVENTIONS

Culturally Responsive Diabetes Interventions within the Context of American Indian and Alaska Native Health

by

Leilani Freeman

An undergraduate honors thesis submitted in partial fulfillment of the requirements for the degree of

Bachelor of Science

in

University Honors

and

Community Health Education

Thesis Adviser

Dr. Kelly Gonzales

Portland State University 


\title{
CULTURALLY RESPONSIVE DIABETES INTERVENTIONS
}

\begin{abstract}
This inquiry examined culturally responsive diabetes interventions within the context of American Indian and Alaska Native (AI/AN) health. The role of history, culture, and resilience in shaping these approaches was determined. Additionally, past instances of abuse from healthcare workers and researchers highlighted the need for culturally competent education. A combination of a literature review and ethnography from events hosted by the local Portland, Oregon AI/AN community helped to address these questions and concerns. This study found that identifying determinants of health using Community-Based Participatory Research (CBPR) is the most effective. The health disparities experienced by AI/AN peoples today are predominantly due to a history of forced removal, genocidal tactics, and detrimental environmental policies. The main elements of a diabetes intervention that takes this history into account includes, connection to culture and the land, education on historical/ intergenerational trauma, and focusing on resilience and tribal sovereignty. The use of traditional foods, community gardens, and holistic fitness programs are some examples of strategies being used to treat diabetes by AI/AN peoples today. Future research should examine how the experiences of Indigenous peoples can better guide those in the field of public health working to achieve health equity for all.
\end{abstract}


CULTURALLY RESPONSIVE DIABETES INTERVENTIONS

\section{Introduction}

Obesity and type 2 diabetes (hereinafter "diabetes") are found in record-breaking rates across the globe, however certain ethnic/racial communities have been disproportionately affected (Leadership for Healthy Communities, 2010). American Indians and Alaska Natives (AI/AN) have some of the highest rates of diabetes in the world (Blakeley \& Park, 2004) and diabetes has become a significant threat to the health of AI/AN children (Blakeley \& Park, 2004). AIs are also much more likely to experience complications from diabetes, these complications are numerous and can have negative effects on physical, social, emotional, and financial wellbeing (Mitchell, 2012).

In general, most diabetes interventions focus on individual behavior change and cultural competency trainings are not often institutionalized within the professional or academic setting (Wallerstein \& Duran, 2006), which may result in negligence and harm. Only recently has research begun to consider the broader context that may influence behavior in the first place (Mitchell, 2012). For example, diabetes education programs may instruct patients to eat a prescribed diet, but they do not address the fact that many people live on limited income, do not have transportation, and live in areas where the nearest grocery store with fresh, healthy, and affordable foods is at least 20 miles away (Mitchell, 2012). These types of intervention programs are typically successful for individuals who come from advantageous backgrounds, but do not address the complexities of diabetes in AI/AN nations (Mitchell, 2012). Determinants of health including, environmental, social, economic, and political factors substantially influence health disparities, but are often left out of the conversation (Mitchell, 2012). The term 'health disparities' will be used to refer to the racial/ ethnic disparities in health that exist within the United States. As seen in Figure 1, AI/ANs experience higher rates of diabetes and heart disease 


\section{CULTURALLY RESPONSIVE DIABETES INTERVENTIONS}

than any other racial group in the country. When certain health outcomes are seen to a greater or lesser extent between populations, a disparity exists ("Disparities", n.d).

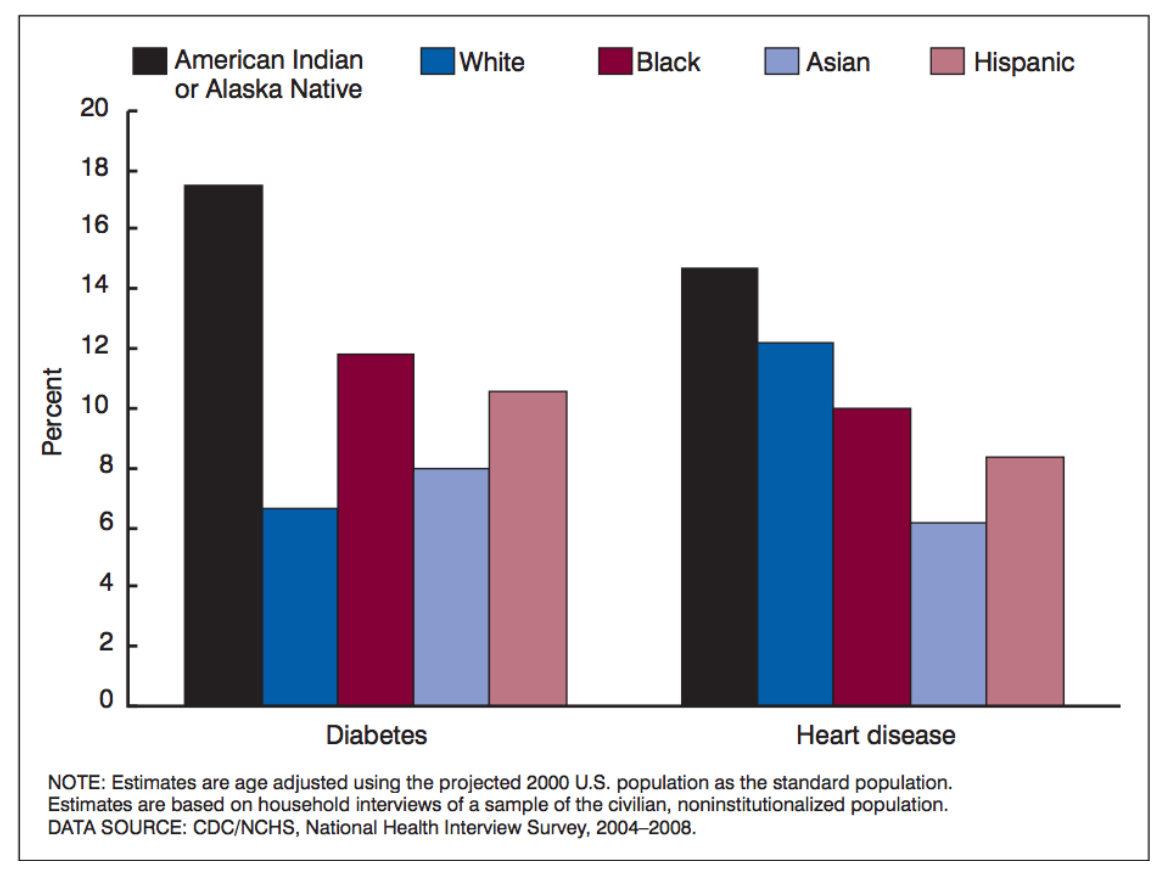

Figure 1. Percentage of adults aged 18 years and over who have ever been diagnosed with diabetes, and percentage of adults aged 18 years and over who have ever been diagnosed with heart disease, by race and ethnicity: United States, 2004-2008. Adapted from "National Health Statistics Reports", by P.M Barnes, P.F Adams, and E. PowellGriner, 2010, Retrieved from https://www.cdc.gov/nchs/data/nhsr/nhsr020.pdf. Copyright 2010 by CDC. Adapted with permission.

It is important for health practitioners to examine how such great health disparities arose by exploring the Social Determinants of Health (SDOH). For example, food insecurity, or having the limited availability or ability to obtain nutritionally adequate and safe foods, is one serious issue that many AI people face (Jernigan, Salvatore, Styne, \& Winkleby, 2011). One of the greatest obstacles is access to traditional foods (Newberg, 2013). Many AI people consider the use of traditional foods and practices vital for regaining health, the tribal economy, and maintaining cultural practices (Mitchell, 2012). Following displacement from ancestral lands, Indigenous peoples were excluded from areas where food used to grow, and environmental destruction from pollution, logging, and industrial farming has compromised harvest areas 
CULTURALLY RESPONSIVE DIABETES INTERVENTIONS

(Newberg, 2013). Using the SDOH perspective, health professionals and AI/ANs can begin to understand that negative health outcomes, such as diabetes and obesity, are a response to colonization and unjust conditions rather than an individual responsibility (Mitchell, 2012).

This inquiry will explore: What are culturally responsive health interventions within the context of AI/AN health, and what role has history, culture, and resilience had to shape these practices and approaches? While the published literature shows that culturally responsive health interventions are important to improving recruitment, retention and ultimately health outcomes for populations of color, few such programs exists in general and these resources are even more scant with regard to AI/AN populations (Roubideaux, 2002). Therefore, a second aim of this work will explore various "calls to action" and efforts that aim to address this gap in the field of public health.

\section{Methods}

In order to address how such striking health disparities arose and persist; this inquiry will examine the history of research in Indian Country. AI/ANs have a history of maltreatment perpetrated by the healthcare and research community. It is therefore crucial to investigate how this history continues to have an impact today. This research used a combination of information gleaned from the published literature as well as from events that relate to health and healing, hosted by the local Portland, Oregon AI/AN community. The literature review includes three sections: the history of research in Indian Country, elements of an effective diabetes intervention, and examples of effective diabetes interventions. My personal reflections from the in-person events will also be presented to supplement the literature. I will end with a discussion of key points from this work and implications for future research.

\section{Evidence}


CULTURALLY RESPONSIVE DIABETES INTERVENTIONS

\section{The History of Research in Indian Country}

When addressing health disparities experienced by AI/AN populations it is important to consider the role of history. Historical and recent instances of unethical research in Indian Country have generated mistrust in AI communities (Pacheco et al., 2013). The psychological barriers of scientific mistrust and past traumas endured by AIs must be overcome in order to move forward with effective and beneficial research (Pacheco et al., 2013). In this section, the role of history in influencing culturally competent approaches will be determined by exploring the inclusion of colonialism as a SDOH and the notion of historical trauma. I will provide examples of colonial practices that have had a direct and lasting effect on AI/AN health as well as examples of unethical research and medical practices, including the genetics testing with the Havasupai Nation and the nonconsensual sterilization of AI women. I will end with a brief discussion on what is being done to ensure that similar instances do not occur again.

Czyzewski (2011) asserts that when health disparities exist globally between Indigenous and settler populations, their shared history becomes all the more relevant and significant when addressing this gap. Determinants of health are more specific for Indigenous peoples compared to that of the mainstream population (Commission, 2007). This is partly due to the way health is conceptualized by Indigenous people as opposed to the Western, biomedical definitions (Commission, 2007). This implies that the traditional framework of the SDOH perspective must be adjusted in order to include everyone (Czyzewski, 2011).

Czyzewski uses the term colonialism as opposed to post-colonialism because several authors and organizations recognize that colonialism has never ceased. Wesley-Esquimaux (2007) notes that the history of colonialism continues to affect public policy through today and entire communities are still recovering from the impact of colonial legislation and assimilationist 


\section{CULTURALLY RESPONSIVE DIABETES INTERVENTIONS}

tactics perpetrated by the government. The inclusion of colonialism in the mainstream SDOH framework recognizes the experiences of Indigenous peoples and helps gives rationale as to why these inequities continue to occur (Czyzewski, 2011). The current model that looks at the population as a whole may contribute to an 'incorporation' (Commission, 2007) agenda or to the normalized invisibility of the experiences of Indigenous peoples (Czyzewski, 2011). It is therefore imperative to incorporate an Indigenous perspective in conventional frameworks. Some examples of colonial policies that have had a direct effect on the high prevalence of diabetes in Indian Country include, the residential schooling system, land dispossession, and the lack of access to traditional food (Czyzewski, 2011).

Since European contact to North America, AI people have been forcibly removed from their homeland by governmental authorities to areas unfamiliar to them (Dobyns, 1984). During what is known as the "Termination" period (1946-1964), the federal government attempted to end their trust relationship with AI nations by breaking treaties and executive orders (Mullan, 1989). Tribal nations were no longer considered sovereign, all federal programs were abolished, including health and education programs, tribal lands were transferred to the state, the tax exemption ended, and state judicial authority was imposed (Pacheco et al., 2013). AI/AN language and religious practices were also outlawed and people were "discouraged" from using traditional AI practices including dances, rituals, and traditional healers (Crosby, 1976). Regulations also evolved to include other offenses, such as the unauthorized leave of absence from the reservation (Crosby, 1976). Moreover, the federal government's Indian Education Program was created specifically to extinguish AI culture (Adams, 1997). As a result of this program, AI children were removed from their families and forced to attend residential boarding schools (Adams, 1997). 


\section{CULTURALLY RESPONSIVE DIABETES INTERVENTIONS}

The residential schooling system imposed by European settlers has had profound effects on Indigenous health. Justice Sinclair, the chair for the Truth and Reconciliation Commission of Canada, stated that the residential schooling system has had an effect on all Indigenous peoples of North America whether directly or indirectly (Czyzewski, 2011). Beginning in the 1860's, AI children were removed from their homes and sent to schools operated by the Roman Catholic Church, Church of England, United Church, or Presbyterian Church, and later the Government of Canada (Czyzewski, 2011). Children represent the future and their removal had profound implications including emotional suffering, the loss of future leaders, and the ability to pass on culture and language (Evans-Campbell, 2008). The research has shown that suicide rates are high for the not only the boarding school survivors, but for their children as well (Elias et al., 2012). This shows that trauma can be passed down intergenerationally, from the survivors to their children, and that unethical practices can continue to create detrimental effects even after being outlawed.

The study of trauma is pertinent to assessing the health conditions experienced by AI/ANs. Evans-Campbell (2008) indicates that the notion of historical trauma, an example of intergenerational trauma, is one of the most promising concepts to emerge in recent literature. The intergenerational transmission of historical trauma can occur on both an interpersonal and societal level (Evans-Campbell, 2008). On an interpersonal level, intergenerational transmission can occur either directly or indirectly. During direct transmission, children may internalize the experiences they learn about from their families and suffer similar psychological problems (Evans-Campbell, 2008). In the case of indirect transmission, traumatic events could lead to poor parental mental health, which can increase stress in children (Auerhahn \& Laub, 1998). On the societal level, the effects of an event may include losses to Indigenous "ways of life" that can 


\section{CULTURALLY RESPONSIVE DIABETES INTERVENTIONS}

continue to have an effect until those losses are replaced (Evans-Campbell, 2008). The concept of historical trauma has proven to be very popular with $\mathrm{AI} / \mathrm{AN}$ peoples, indicating that it incorporates the experience of individuals and communities that most models overlook (EvansCampbell, 2008).

The statistics on how often people thought about specific historical losses is quite significant. For example, in a study presented by Evans-Campbell, about one fifth (18.2\%) of respondents said that they thought at least once a day about the loss of Indigenous land, more than one third (36.3\%) had daily thoughts about the loss of Indigenous language in their community, and more than one third (33.7\%) experienced daily thoughts about loss of culture. A significant percentage of respondents (45.9\%) thought daily about alcoholism and its impact on the community and although the nations involved in this particular study were not apart of the residential school policy, about $18 \%$ of respondents thought about the losses associated with boarding school at least once per week (Evans-Campbell, 2008). Evans-Campbell notes that given the staggering number of events endured by ancestors, AV/AN people of today tend to downplay their own personal experiences. One suggested method of social healing includes mourning those losses as well as replacing them with something new and healthy in the community (Evans-Campbell, 2008).

Interventions should aim to work at both the familial and community level. A number of tribal nations have developed community-level healing processes by reestablishing traditional social practices such as canoe journeys and traditional hunting practices (Evans-Campbell, 2008). Evans-Campbell argues that the final and perhaps most important implication for future scholarship must consider resilience and healing surrounding trauma in $\mathrm{AI} / \mathrm{AN}$ communities. For example, while trauma has had negative outcomes, it could also be argued that in Indigenous 


\section{CULTURALLY RESPONSIVE DIABETES INTERVENTIONS}

communities, a history of trauma has enhanced community ties and has highlighted the importance of retaining culture and tradition (Evans-Campbell, 2008).

In the work that follows I will outline some examples of harmful research and medical practices administered by the research community and governmental agencies. I will begin with the lawsuit that occurred as a result of unethical genetics research between the Havasupai Nation and Arizona State University. I will then discuss the nonconsensual sterilizations of AI women perpetrated by the Indian Health Services (IHS).

In 2003 the Havasupai Nation in Arizona found that their DNA samples collected for genetic studies on diabetes had also been used for studies on schizophrenia, migration, and inbreeding without their approval (Garrison \& Cho, 2013). This was the first time the Havasupai Nation had ever allowed researchers to take their blood, as blood holds significant cultural and spiritual worth to the Havasupai Nation (Drabiak-Syed, 2010). As noted by Dr. Frank Dukepoo, a geneticist of Hopi and Laguna ancestry, any part of the human body is sacred to AIs. He goes on to say that, "for an Indian it is not just DNA, it's part of a person, it is sacred, with deep religious significance. It is part of the essence of a person" (Petit, 1998, as cited by Santos, 2008, p. 4). The Havasupai believe that when an individual dies, they cannot pass on to the next world until they have all of their possessions (Pacheco et al., 2013). Therefore, the proper return of their blood samples was extremely significant.

The Havasupai's DNA samples were not only used without their permission or regard for cultural and spiritual beliefs, but the findings from this research also harmed the Havasupai Nation. The research on schizophrenia, inbreeding, and population migration theories did not benefit their nation in any way and instead subjected them to stigma and emotional and mental anguish (Drabiak-Syed, 2010). For example, the research on migration suggested that the 


\section{CULTURALLY RESPONSIVE DIABETES INTERVENTIONS}

Havasupai migrated from a geographic location inconsistent with their worldview (Santos, 2008). Furthermore, the findings from the diabetes testing hypothesized that the high prevalence of diabetes was a result of a nutrient deficiency in pregnancy (Rubin, 2004). No intervention efforts were made as a result of these findings, indicating that the best interest of the Havasupai Nation was not considered (Santos, 2008). People with diabetes from the Havasupai Nation now have to be treated with dialysis because they did not seek medical treatment in time due to the fear and mistrust that occurred as a result of this project (Boomersbach, 2008).

This case provoked discussions within both the genetics world and AI/AN communities about what this means for tribal nations who already have a distrust of researchers and for researchers who are committed to adhering to ethical guidelines (Garrison \& Cho, 2013). The publicity surrounding the lawsuit has provided opportunities for researchers to learn about the case and discuss issues surrounding informed consent and secondary use of samples (Garrison \& Cho, 2013). When the knowledge of the Havasupai case was assessed most of the Institutional Review Board chairs (12 out of 13) recognized an ethical concern while only half (7 out of 13) of the researchers were able to identify ethical issues (Garrison \& Cho, 2013). Cultural practices and traditions were not taken into account in this case and many researchers remain unaware of the impact and significance. Despite the widespread attention, many questions from the case remain and there is still little guidance on how to deal with these types of cases in the future (Garrison \& Cho, 2013).

This example illustrates the immense harm researchers have caused to both the Havasupai Nation and AIs who also developed medical mistrust as a result of this project. Santos (2008) notes that although there are conversations between researchers, scientists, and bioethicists surrounding the ethics, benefits, and risks of research in Indigenous communities, 


\section{CULTURALLY RESPONSIVE DIABETES INTERVENTIONS}

Indigenous people are rarely a part of these discussions (Santos, 2008). Their perspectives, even when heard, are often ignored because their concerns often require more time, consideration, and effort, and do not align with the structure of the Euro-American research tradition (Santos, 2008). According to the study published by Garrison and Cho (2013), researchers have yet to learn important lessons from the Havasupai case and without successful research ethics education, history is likely to repeat itself. It is imperative that researchers learn about culturally appropriate research methods in order to maximize the beneficial outcome for participants and prevent unintentional harm (Pacheco et al., 2013).

Another devastating example of medical trauma endured by AI peoples was the nonconsensual sterilizations of AI women. Between 1970 and 1976 the IHS sterilized between 25 to 50 percent of AI women (Lawrence, 2000). The allegations against the IHS included: the use of coercion to get signatures on consent forms, improper consent forms, and the lack of an appropriate waiting period (at least seventy-two hours) between the signing of a consent form and the surgical procedure (Lawrence, 2000). Mary Ann Bear Comes Out, a member of the Northern Cheyenne Nation, conducted a survey on the Northern Cheyenne Reservation and Labre Mission grounds. The survey concluded that the rate of sterilizations reduced birth rates among this group by more than half over a five-year period (Lawrence, 2000). The sterilization of AI women affected not only individuals, but their family and friends as well. Many marriages ended in divorce and numerous friendships became estranged (Lawrence, 2000). The women had to cope with higher rates of marital problems, alcoholism, drug abuse, psychological difficulties, shame, and guilt (Lawrence, 2000).

The IHS damaged tribal communities by taking away a woman's right to reproduce, leading to the loss of respect from other tribal nations and the loss of political power in tribal 


\section{CULTURALLY RESPONSIVE DIABETES INTERVENTIONS}

councils (Lawrence, 2000). Lawrence (2000) identified that the number of people in the community affects a community's level of power within the tribal government. Therefore, the lower census count could also interfere with the federal services a tribal nation receives. Some AIs believe that the sterilizations also affected the tribe's economic base and sovereignty (Lawrence, 2000). Lee Brightman, president of United Native Americans Inc., argues that "the sterilization campaign is nothing but an insidious scheme to get the Indians' land once and for all” (Lawrence, 2000, p. 412). Dr. Connie Pinkerton-Uri, a Choctaw-Cherokee physician, conducted a study and found that the IHS facilities singled out full-blood AI women for sterilization procedures (Lawrence, 2000). She goes on to say that she does not believe the sterilizations were an attempt to exterminate AIs, but a result of physicians distorted thinking that the solution to poverty was to not allow births (Lawrence, 2000). Mary Crow Dog, a Lakota member of the American Indian Movement, said that as a result of these sterilizations, she, like many AI women, felt that they had a personal responsibility to make up for the genocide suffered by their people in the past (Lawrence, 2000). Numerous studies of AI cultures and family structures found that children are important not only to the joy they bring parents, but because group survival is an important aspect of tribal culture (Lawrence, 2000). Katsi Cook of the Mohawk Nation stated that "women are the base of the generations. Our reproductive power is sacred to us" (Lawrence, 2000).

The evidence shows that the aftermath of the sterilizations drastically changed all aspects of AI life. Relationships between AIs and governmental agencies, as well as relationships between husbands and wives, and mothers and children were severely damaged. There was also an immense amount of harm caused to the individual women who were sterilized, as their reproductive rights are sacred and a part of their identity. Despite the extensive harm that 


\section{CULTURALLY RESPONSIVE DIABETES INTERVENTIONS}

occurred, the care of the IHS has improved as a result. In 1976, the Indian Health Care Improvement Act was passed, giving tribal nations the right to manage IHS programs (Lawrence, 2000). Many tribal nations have taken over IHS facilities and their participation has strengthened communities (Lawrence, 2000).

It is important for researchers and healthcare workers to learn about the immense harm perpetrated by both the medical and research community because AI/ANs do not typically differentiate between the two; these instances are seen as being perpetuated by the same people (Pacheco et al.,2013). This means that mistrust is deep-rooted and researchers must take extra care when moving forward. The Center for American Indian Community Health (CAICH) has taken the steps necessary to avoid future harm in researcher practices by educating AIs about their rights, empowering them to assert those rights, and by protecting them from unethical research (Pacheco et al., 2013). When working with people of color, researchers will often avoid talking about previous abuses (Pacheco et al., 2013). CAICH has created a model that facilitates dialogue between researchers and $\mathrm{AI} / \mathrm{AN}$ communities that have endured harmful research practices and medical misconduct (Pacheco et al., 2013). An open dialogue ensures that past instances of unethical research are addressed and that conversations are had on how to make certain that similar instances do not occur again (Pacheco et al., 2013). CAICH has also created a Law and Policy Core that protects AI research participants by empowering them to make informed decisions. More research is needed to determine the most effective methods of addressing health disparities in AI nations however, research cannot be done effectively until the cycle of scientific mistrust and medical abuse is broken (Pacheco et al. 2013).

\section{Elements of Effective Interventions}




\section{CULTURALLY RESPONSIVE DIABETES INTERVENTIONS}

In the following section I will explore elements of effective and culturally sensitive interventions. I will begin by discussing the current barriers in the AI healthcare system and the ways in which the delivery of healthcare can be improved. I will then highlight the need for including the community in every step of the research process using the Community-Based Participatory Research (CBPR) principles. Next, I will show the importance of focusing on resilience and community strengths by reviewing an Indigenist Stress-Coping Model (Walters \& Simoni, 2002) that incorporates culture in the process of healing. I will conclude by exploring the most effective methods for building healthy research relationships within tribal communities.

The federal government has a responsibility to provide adequate healthcare for AIs (Blakeley \& Park, 2004) AI nations signed over 400 million acres of tribal land to the United States government with the understanding that they would provide health care services along with other benefits (Blakeley \& Park, 2004). However, despite the increase in value of land, AI Healthcare remains poorly underfunded (Blakeley \& Park, 2004). While an increase in funding is needed, significant reform is also needed in cultural competency training. In the 2004 United States Congress report it was noted that the importance of cultural competency training is recognized however, the IHS does not have a specific budget set aside for this training. In addition to the lack of training, the IHS does not provide formal interpreters to its patients, which is an additional obstacle to adequate health services for AIs who maintain their traditional language (Blakeley \& Park, 2004). Racial and ethnic bias and discrimination also contribute to AI health disparities (Blakeley \& Park, 2004). Studies have found that unconscious bias is more common than conscious discrimination and that these biases can lead practitioners to make inappropriate decisions that affect the overall quality of care (Blakeley \& Park, 2004). This is an example of why it is important for researchers and healthcare providers to reflect upon their 


\section{CULTURALLY RESPONSIVE DIABETES INTERVENTIONS}

preconceived biases about various racial and ethnic groups in order to prevent these types of mistakes from occuring. It is also important to recognize that improving healthcare for AIs is more than just a medical treatment and involves a holistic approach incorporating education, proper housing, economic opportunity, as well as empowerment through self-determination and self-governance (Blakeley \& Park, 2004).

CBPR is an example of an alternative research method that combines education and social action to improve health outcomes and reduce health disparities (Wallerstein \& Duran, 2006). CBPR focuses on fostering relationships between academic and community partners with the principles of mutual learning and benefit, and long-term commitment while integrating community theories and participation into research efforts (Wallerstein \& Duran, 2006). CBPR recognizes the important contributions of community members and combines knowledge from all parties in order to create action and social change (Minkler Wallerstein, 2003).

CBPR is a relatively new and emerging research practice that still faces challenges and paradoxes (Wallerstein \& Duran, 2006). As CBPR has progressed, issues have arisen that question the role of power, privilege, participation, community consent, and racial and/or ethnic discrimination (Wallerstein \& Duran, 2006). Privilege in this context refers to social inequality in regard to ethnic or racial category. Researchers enter communities with their own set of "baggage", whether that be their ethnicity, socioeconomic status, background, or affiliated University that may have a history of research with that community (Wallerstein \& Duran, 2006). Researchers must be aware of their own privilege influencing their biases in order to protect participants from discrimination and harm.

In addition to the issues of power, privilege, and racial/ ethnic discrimination, the mutuality and benefit of the research project must be carefully assessed. Wallerstein and Duran 


\section{CULTURALLY RESPONSIVE DIABETES INTERVENTIONS}

(2006) ask the question, "How do we address the reality that different stakeholders may and do have different goals of participation and different knowledge needs, and have different expertise to participate more actively at different stages?” (p. 314). The objective of researchers is often different from that of the community's desire to improve programs and services (Wallerstein \& Duran, 2006). It is important to discuss these issues throughout the research process in order to maximize community benefit by decreasing the length of time needed to create change, even though publication from the research project may be a long-term process (Wallerstein \& Duran, 2006). The evidence shows that incorporating community expertise and engaging participants in research has positive outcomes on health (Wallerstein \& Duran, 2006). Participation improves program development with greater efficiency, sustainability, and the more equitable distribution of services (Isham, Narayan, \& Pritchett, 1995; Manikutty, 1997; Narayan, 1992). It is conclusive that CBPR benefits both community members, who are included in the research process, and researchers who aspire to deliver long-term improvements in health.

Another element of an effective health intervention incorporates cultural resilience. Walters and Simoni (2002) present a way of conceptualizing Indigenous women's health through an "Indigenist" Stress-Coping Model. This model is specifically aimed to incorporate the experiences of AI women who have held sacred and central positions in Indigenous nations for centuries (Walters \& Simoni, 2002). Indigenous women hold powerful roles as sacred life givers, teachers, socializers of children, healers, doctors, seers, and warriors (Kauffman \& Joseph-Fox, 1996). Their status in these roles has allowed them to form the center of Indigenous resistance to colonization (Kauffman \& Joseph-Fox, 1996). Kauffman and Joseph-Fox (1996) argue that the health of tribal nations in many ways depends upon the women. The United States government has attempted to disempower Indigenous women as a way of exerting colonial domination over 


\section{CULTURALLY RESPONSIVE DIABETES INTERVENTIONS}

Indigenous nations (Jaimes \& Halsey, 1992). The sterilizations discussed earlier are one example of how the US government tried to destabilize Indigenous communities by harming their women. Another example that occurred among the Cherokee, a traditionally matriarchal society, was when British colonizers "educated" Cherokee males about European patriarchal ways (Jaimes \& Halsey, 1992). They also encouraged marriage to non-Native women and privileged mixedblood male offspring in nation-to-nation negotiations (Jaimes \& Halsey, 1992). These examples further constitute the notion of "historical trauma" and call for stress-coping models that incorporate the experiences of Indigenous people.

The "indigenist" stress-coping model modifies traditional models with cultural aspects that buffer the effects of life stressors on negative health outcomes (Walters \& Simoni, 2002). Cultural buffers include identity attitudes, enculturation, spiritual coping, and traditional health practices (Walters \& Simoni, 2002). Research on Indigenous peoples has suggested that identity attitudes, such as the extent to which one internalizes attitudes towards oneself and one's group, are important for enhancing self esteem, coping with psychological distress, and avoiding depression (Walters, 1999). Additionally, enculturation, or the process by which people learn about and identify with their culture, can either lessen the negative effects of stressors or enhance buffers, which further decreases the likelihood of negative health outcomes (Walters \& Simoni, 2002).

The "indigenist" stress-coping model highlights the importance of maintaining cultural practices, particularly for AI/AN peoples. Walters and Simoni assert that, identifying the vulnerabilities of Indigenous women within the context of their historical and contemporary oppression while capitalizing on their strengths illustrates an Indigenous perspective that can aid public health researchers and practitioners in promoting the health and wellbeing of individuals 


\section{CULTURALLY RESPONSIVE DIABETES INTERVENTIONS}

and ultimately the health and wellbeing of indigenous nations. Furthermore, spiritual methods of coping are also effective at mediating stressful life events and improving physical and mental health (Walters \& Simoni, 2002). Other forms of traditional healing practices such as medicinal root teas and sweat lodges (used for ritual purification) have intrinsic benefits that support positive health outcomes among AI/ANs (Walters \& Simoni, 2002). It is important to recognize and respect traditional methods of healing, even when the westernized framework for "evidenced-based" practices has not been applied.

Cultural values are foundational to the research and health intervention process (National Congress of American Indians, 2012). Researchers must aim to respect, appreciate, and understand Indigenous knowledge and how it applies to research (National Congress of American Indians, 2012). Respecting a tribal nation's knowledge allows for the focus to be on their strengths and ensures that the research outcome will be beneficial to everyone (National Congress of American Indians, 2012). Researchers should also involve key tribal decisionmakers in all stages of the research process, which is especially important when no institutional review board or Ethics Committee is in place (National Congress of American Indians, 2012). The National Congress of American Indians (NCAI) Policy Research Center and the Montana State University (MSU) Center for Native Health Partnerships (CNHP) collected information from individuals who currently work with or want to work with tribal nations, regarding their advice for strengthening research relationships. They summarized seven common themes which include: listen and pay attention, respect cultural and local knowledge, leave pre-conceived research assumptions behind, have personal integrity, have shared goals, learn about the nations you are working with, plan for sustainability, and provide community benefit (NCAI, 2012). 


\section{CULTURALLY RESPONSIVE DIABETES INTERVENTIONS}

Being an active listener is the key first step to building research relationships with AI/AN communities as it indicates that the researcher is engaged in learning about their needs. In addition, respecting cultural knowledge includes respecting expertise and not just academic degrees (NCAI, 2012). Non-Native researchers may not always be aware of the dominance of their worldview or see the need to embrace community values (NCAI, 2012). It is therefore important to challenge one's own assumptions and pre-conceived theories before and after the research process. Researchers must recognize that building trust takes time. In the survey conducted by the NCAI Policy Research Center and the MSU CNHP, participants noted the importance of building individual relationships and "being yourself" while also recognizing that you are not "by yourself" (NCAI, 2012). This allows researchers to be attentive to and value the knowledge of others. When shared knowledge and worldviews drive the research process, project outcomes are beneficial to everyone and their effects are strengthened (NCAI, 2012). Long-term positive outcomes, as defined by the community, are vital for building trust and should be discussed at the beginning of the research process (NCAI, 2012).

The evidence presented shows that community driven projects are the most effective and sustainable. Health professionals must resist the temptation to enter communities as "experts" by attempting to control project outcomes (Roubideaux, 2002). It is much more productive to serve as a resource and to help build local capacity (Roubideaux, 2002). Moreover, health practitioners should learn about the health challenges that AI/ANs face as well as about complexities of the specific nations they serve, as every nation is diverse with their own set of needs and expectations (Roubideaux 2002). Focusing on community strengths and resiliencies is vital to improving health outcomes and promoting sustainability.

\section{Examples of Effective Interventions}




\section{CULTURALLY RESPONSIVE DIABETES INTERVENTIONS}

In the following section I will explore examples of effective interventions that address obesity and associated health conditions, including diabetes. I will begin with an intervention method that identified "upstream" approaches to disease prevention using a SDOH perspective. I will also explore a CBPR intervention study that addressed food insecurity by identifying

community barriers in a culturally competent way. I will end by describing traditional diets and how tribes across the Pacific Northwest are increasing their access to traditional foods.

An example of a diabetes intervention incorporating a SDOH perspective promoted health literacy by discussing the loss of traditional food systems and how it has affected the community's diet. Health professionals worked with tribal historians to provide a timeline of the changes made to the tribe's diet in relation to the environmental, political, and legislative policies that they were already familiar with (Mitchell, 2012). This allowed community members to better understand their current dietary challenges, why they have occurred, and how to act. For example, the Gila River Indian Nation has traced a major change in diet and food insecurity to the damming of waters that drastically reduced the level of the Gila River and led to a drought, interfering with the tradition of farming and irrigation (Warne, 2006). An awareness of the SDOH allows tribes to reinforce the importance of cultural practices that use traditional knowledge of AI food development practices (Mitchell, 2012).

An example of a CBPR intervention method addressed food insecurity on the Round Valley reservation. Over $85 \%$ of people, in some AI reservations, receive food assistance from the US Department of Agriculture's Food Distribution Program that typically consist of packaged foods high in fat, salt, and sugar (Harris \& Harper, 2001). Surveys conducted by the Round Valley Indian Health Center have found that $68 \%$ of community members aged 20-74 years are obese, which is double the national average for all US adults (Jernigan et al., 2011). 


\section{CULTURALLY RESPONSIVE DIABETES INTERVENTIONS}

The intervention on the Round Valley reservation conducted a community assessment using the Tool for Health and Resilience in Vulnerable Environments (THRIVE) and identified potential barriers to healthy and culturally appropriate foods. THRIVE is an action-oriented tool that aims to increase collaboration between communities and agencies when identifying solutions by engaging key community members in the assessment of community needs and their root causes (Jernigan et al., 2011). This tool is specifically used to promote positive health outcomes for racial and ethnic minorities. Following the assessment, the project implemented policies to address the identified barriers, which had positive results for the community.

The THRIVE tool was tailored for cultural appropriateness with the use of digital storytelling for local relevance and focus groups to facilitate discussion surrounding the information presented (Jernigan et al., 2011). A digital story is described as, "a short, first person video-narrative created by combining recorded voice, still and moving images and music or other sounds" (Gubrium, 2009). Storytelling is consistent with AI tradition and was used to accompany each of the THRIVE factors which included, racial justice, jobs and local ownership, education, social networks and trust, participation and willingness to act for the common good, acceptable behaviors and attitudes, what's sold and how it's promoted, parks and open space, getting around, housing, air, water, and soil, as well as arts and culture (Jernigan et al., 2011). Focus groups were used instead of an online survey because they allowed community members to discuss the environmental factors affecting their health and identify strategies for policy change (Jernigan et al., 2011).

This study found that 'racial injustice' was the issue of most concern in all of the five focus groups. Participants discussed the lack of Native-owned businesses in their community as well as the absence of Native-owned stands at the weekly farmer's market as a barrier to healthy 


\section{CULTURALLY RESPONSIVE DIABETES INTERVENTIONS}

food (Jernigan et al., 2011). The weekly farmer's market is located in a mostly white area of town with cash-only sales leaving Native community members feeling unwelcome (Jernigan et al., 2011). In addition, the participants noted that without a living wage it was difficult to pay for gas in order to travel two hours to the nearest grocery store (Jernigan et al., 2011). Because of this the community had to rely on packaged and canned goods from the USDA FDPIR program at the local grocery store (Jernigan et al., 2011). As previously mentioned, these foods are often high in fat, salt, and sugar, while low in fiber, which has been shown to increase the risk of obesity and diabetes (Jernigan et al., 2011). The local grocery store did not contain any culturally appropriate foods or bulk items and the foods that were available were over priced (Jernigan et al., 2011). Focus group members also felt that their community lacked playgrounds, parks, sidewalks and streetlights, making it difficult to get outside and engaged in exercise (Jernigan et al., 2011).

Following this method of data collection, policies were developed that involved key stakeholders including, owners of the farm, grocery store and gas station in order to address the identified barriers (Jernigan et al., 2011). A Community Supported Agriculture (CSA) program was established that designated a portion of the fresh produce to be sold in the local community, and local growers would be reimbursed for any unsold produce (Jernigan et al., 2011). The CSA program also created job opportunities in the Valley. The Round Valley Indian Health Center received funding for a pilot program to use CSA produce for Round Valley Unified School District school lunches (Jernigan et al., 2011). They also received funding to supply CSA produce through the USDA FDPIR commodity food distributions on the reservation (Jernigan et al., 2011). Furthermore, Electronic Benefit Transfer machines were made available at the local farmers' market, which allowed residents to use their food assistance funds to buy fresh produce 


\section{CULTURALLY RESPONSIVE DIABETES INTERVENTIONS}

(Jernigan et al., 2011). Additionally, shelf-space at the local grocery store was made available to promote fresh fruits and vegetables (Jernigan et al., 2011). Bulk items and traditional/ special foods for diabetes were also made available (Jernigan et al., 2011).

To address the environmental concerns, the tribal council and the health clinic wrote a grant to create a space for physical activity (Jernigan et al., 2011). The proposed bike and walking path is to include culturally appropriate art and educational exhibits designed by AI community members (Jernigan et al., 2011). The clinic also created 'Bike Wednesday' as a way to offer group rides and free bike repair. The culturally appropriate and upstream approaches to health promotion in this study proved to have a beneficial outcome for the community it served.

The CBPR intervention example discussed above identified that traditional diets are best suited for reducing diabetes among AI/ANs. Traditionally, Indigenous diets contained high amounts of animal protein, nutrient dense foods, and were low in fat or high in marine sources of fat (Compher, 2006). Traditional diets were typically high in omega-3 fatty acids as well as docosahexaenoic acid and eicosapentaenoic acid found in fish; evidence has shown that these nutrients decrease the risk of cardiovascular disease (World Health Organization, 2002).

Research has also shown that the increased intake of traditional foods decreases the amount of saturated fats and the omega-6:omega-3 fatty acid ratio, which is a protective risk factor of cardiovascular health (Simopoulos, 2008). Moreover, traditional foods come from wild plants, rich in micronutrients (Grivetti \& Ogle, 2000). Plants are not only used as food, but as traditional medicine as well, offering therapeutic effects from their consumption (Earle, 2011).

Furthermore, Indigenous American agriculture was largely based on corn (Dunbar-Ortiz, 2014). Mesoamericans cultivated squash and beans, which along with corn created a complete protein (Dunbar-Ortiz, 2014). The collection of food was very physically demanding and included 


\section{CULTURALLY RESPONSIVE DIABETES INTERVENTIONS}

hunting, fishing, trapping, growing and gathering (Redwood et al., 2008). Indigenous diet consumption patterns arose from a complex and holistic food system that provided both nutritional and spiritual health (Earle, 2011). As discussed earlier, culture is a large part of health and healing for AI/ANs and the collection and consumption of traditional foods is vital to health restoration and connection with the land (Earle, 2011). Among ANs, traditional food consumption is associated with other measures of culture including speaking a Native language, using traditional medicine, and participation in traditional events (Redwood et al., 2008).

Portland's local AI/AN community has made an effort to increase access to traditional foods using community gardens. The Wisdom Gardens in southeast Portland are considered a form of "horticultural therapy" (Newberry, 2013). The garden contains everything from red cedar trees, huckleberries, cranberries, elderberries, and salmon berries to heirloom vegetables, such as Japanese peas, golden beets, beans, and squash. The Wisdom Gardens was created to provide nourishment and education on the importance of Indigenous foods to Portland's tribal community (Newberry, 2013). Marc Anderson, an environmental engineer and diabetes educator who serves on the advisory committee for the Wisdoms Gardens, also a member of the Seminole Nation, advocates for a diet of traditional plant-based foods to reverse diabetes for AI people (Newberry, 2013). The garden not only provides fresh healthy food, but it also allows for people to connect with the earth and their home by working in the garden (Newberry, 2013).

Tribal nations across the Pacific Northwest are working to reestablish food sovereignty and incorporate traditional, local, and healthy foods back into their diet (Newberry, 2013). Many tribes are funding initiatives that increase access to traditional foods. For example, the Confederated Tribes of Siletz Indians, whose ancestral lands spread out across the Central Oregon Coast, is one of seventeen tribal nations initiating a Health Traditions project, funded by 


\section{CULTURALLY RESPONSIVE DIABETES INTERVENTIONS}

a four-year Type 2 diabetes prevention grant from the Centers for Disease Control and Prevention (CDC) to restore culturally appropriate traditional foods (Newberry, 2013). The project aims to improve the health of community members with educational activities that promote the consumption of traditional foods through hunting, gathering, cooking, food preservation, and conservation of natural resources (Newberry, 2013). The project began by holding community meetings to establish their needs. Many community members identified the need for gardening programs, health education classes, and community learning (Newberry, 2013). The Siletz Nation has also developed relationships with private and public land owners in order to obtain areas for annual harvest of traditional foods, including huckleberries and camas, in exchange for management of that land (Newberry, 2013). Additionally, the Siletz Nation is working with the Oregon Department of Fish and Wildlife to increase the passage of lamprey at the Siletz Gorge falls (Newberry, 2013). Lampreys are near extinction in traditional harvest areas, however, each year the tribe harvests lamprey on the Siletz River at Willamette Falls (Newberry, 2013).

Valerie Segrest, a Native foods educator and community nutritionist with the Muckleshoot Indian Tribe, teaches a nutrition course at the Northwest Indian College called "Honor the Gift of Food" (Newberry, 2013). She advocates for a healthy, traditional-foods based diet by asking her students what their ancestors would recognize as food in the grocery store. Students have made creative recipes with traditional foods such as, salmonberry sorbet with wild rose honey, salmon hash, kelp pickles, rosehip jam and nettle pesto (Newberry, 2013). Segrest teaches students to cook with good intentions because in their culture, cooking food for people is one of the holiest things you can do (Newberry, 2013). Segrest notes that Indigenous people have a deep relationship with food and feeding the spirit has to be a part of the conversation on how to 


\section{CULTURALLY RESPONSIVE DIABETES INTERVENTIONS}

create sustainability (Newberry, 2013). This example suggest that healing from dietary related diseases is much more than just about changing the foods people eat, it is about reconnecting with food both spiritually and emotionally.

\section{Reflections}

In the following section I will begin by providing my personal reflections on the 'History of Research' section discussed previously. It is important that I provide these reflections as the information I have learned affected me deeply. In this section I will also provide a summary of the events that I attended hosted by Portland's local AI/AN community. I will end with a reflection upon what I will take away from this work.

When I began reading about the history of research in Indian Country, I was not only shocked by what I learned, but also upset that I had not learned about these events sooner. Previously, I had not learned about the nonconsensual sterilizations of AI women and although I had heard of the boarding schools, the extent of the harm endured was not disclosed. The diabetes research between the Havasupai Nation and Arizona State University was also something that I had not learned about in my public health courses. During my college education I learned about unethical research practices that occurred with African American populations, such as the Tuskegee Study (CDC, 2016). However, the study that occurred with the Havasupai Nation was equally as damaging and unethical, yet many healthcare researchers remain unaware of the significance (Garrison \& Cho, 2014). It was shocking that only about half of the researchers from the Arizona State University research team saw any ethical issues with this research and some had not heard about the case at all (Garrison \& Cho, 2014). This is an example of how researchers may be unaware of the dominance of their worldview. For example, one researcher said that the Havasupai Nation's reaction to this case was the exception and not 


\section{CULTURALLY RESPONSIVE DIABETES INTERVENTIONS}

the rule (Garrison \& Cho, 2014). The researcher believed that if people donated their DNA samples for research, then those people would likely be open to using those samples in as many studies as possible. However, the Havasupai Nation did not share this point of view, as blood holds significant spiritual worth and they had never let researchers take their blood before (Garrison \& Cho, 2014). The studies conducted on inbreeding, schizophrenia, and migration patterns perpetuated harm and did not benefit the Havasupai Nation in any way. If the researchers were aware of the Havasupai Nation's cultural view, perhaps they would have been more likely to understand the significance and how detrimental this research was. This example demonstrates how important it is for researchers to educate themselves on cultural beliefs and historical events.

The boarding schools are another example of a project funded by the United States government that had a major impact on health. After reading about the boarding schools in the literature, I also watched videos of interviews with the survivors. I learned that children were abused physically, emotionally, and spiritually (Debruyn \& Brave Heart, 1998). There were also many instances of sexual abuse (Debruyn \& Brave Heart, 1998). One of the scariest events that a child can go through is being forcefully removed from their parents. Parents bring their children great safety and comfort. I cannot image what it would be like to be taken away from my parents, separated from my siblings, and banned from speaking my native language with the children around me. The inability to speak and converse with others is one additional barrier to coping in a horrendously terrifying situation. The abuse that occurred in boarding schools left many children dead and severely traumatized and many families were not informed of their child's death (Kennedy, 2015). I can understand how people may not trust the government or government-funded programs after such a detrimental project. After children "graduated" from 


\section{CULTURALLY RESPONSIVE DIABETES INTERVENTIONS}

boarding schools, many were unable to communicate with their people in their native language once they returned home (“Canada's residential schools: The Inuit and Northern Experience,” 2015). The documentaries I watched noted how people would return home as somewhere in between two completely different worlds ("Canada's residential schools: The Inuit and Northern Experience," 2015). Many people became frustrated that they did not fit in at home or with the white culture they were brought up in. The government did not provide any opportunity to stay with the western education system and many people were left feeling lost ("Canada's residential schools: The Inuit and Northern Experience," 2015). I do not understand how the United States government could commit such a horrendous act and not be held responsible for the repercussions. I was also surprised at how recently the boarding schools closed. In the United States the schools went as late as the 1960's (REF, Kelly), while in Canada the last boarding school closed in 1994 (Czyzewski, 2011). This history is very recent and the effects continue to be felt today.

The nonconsentual sterilization of AI women was another practice that I found especially disturbing and difficult to read about. The forceful removal of a woman's reproductive power is one of the most personal ways that someone can be attacked. Taking away a family's ability to reproduce dramatically changes their life and ability to plan for the future. From my perspective, sterilizations are worse than an individual murder because as previously mentioned, these procedures reduced birth rates by more than a half over a five-year period (Lawrence, 2000). While having a baby is special for any woman, I learned that AI women hold powerful roles in their society (Walters \& Simoni, 2002). After learning more about their culture, I realized that these sterilizations were even more detrimental than I had once thought possible. The United States government can never undo the damage they have caused; the only way to move forward 


\section{CULTURALLY RESPONSIVE DIABETES INTERVENTIONS}

is to promote an environment that fosters and encourages healthy pregnancies. This is exactly what the Future Generations Collaborative (FGC) aims to do. The FGC is a local collective comprised of agencies and nonprofits that serve Portland's local AI/AN community. The FGC hosted a number of the events that I attended.

The first event I attended was entitled "Indigenous Healing and Celebration." The FGC presented on historical trauma and health inequities. There was also a panel of Multnomah County employees there to discuss traditional AI methods of healing from their heritage. When I first arrived at the event, I followed the sound of the drums to the correct room location. There was a drumming circle there and people were dancing and singing. The sound of the drums was so deep and strong that I could feel my heartbeat synchronizing to the sound. There was something very moving and powerful about hearing people drum and sing with such passion. I knew their music had physical power when the large metal frame from the light above came crashing down.

During this event I heard stories from many people who identify as AI. The first speaker identified as half Black and half AI. He said he found his job with Multnomah County through a project that aims to increase diversity in the workforce. He said he was the first AI out of 99 employees who had been hired through the project. His goal is to represent his community by showing other people that Indigenous people are here and that they are proud. The next speaker also identified as AI and Black. She told us a little bit about her childhood and life experiences. It was not until she was thirteen years old that she found out she had AI heritage. Before this time she grew up disconnected to AI culture. By discovering her heritage and culture she was able to heal using prayers and songs. Culture is now a big part of her life and she continues to teach her 


\section{CULTURALLY RESPONSIVE DIABETES INTERVENTIONS}

children about their ancestry. She wants her kids to grow up knowing who they are and where they came from. She said that culture has been a large part of her health and healing.

The next speaker recited a poem that she wrote called: Indigenous Woman. She talked about what it means to be a woman and what it means to be Indigenous. She said there is more to her than what meets the eye and that she is fighting to be free as an Indigenous woman. One line that stood out to me mentioned how she does not want pity or sympathy, but that she wants people to listen to what she has to say. This stood out to me because as I have learned more about history and trauma, I have felt overwhelmed with sadness and grief. As an ally, I must remember how important it is to move forward and to listen to others about what they might need.

After the first three speakers, members of the FGC came to speak. The FGC is working to improve health among AI/AN communities by identifying and addressing causes of substanceexposed pregnancies that can lead to fetal alcohol spectrum disorder (FASD). Historical and intergenerational trauma plays a large role in the presence of FASDs among this population. The FGC talked about how trauma can be a vicious cycle. When children grow up with a FASD they are more likely to raise their children in a similar environment. The speaker said, that as community-health workers we need to go into the community and ask the community what they need in order to heal. She also said that it is important to recognize that we can never tell someone how to heal, we can only help facilitate that process and step back while people heal on their own.

During this event I learned more about important components of traditional health and healing. I learned that culture is a major part of identity and health. I also learned that the healing process should be self-driven and that health professionals should maintain their role as a 


\section{CULTURALLY RESPONSIVE DIABETES INTERVENTIONS}

resource instead of trying to "fix" everything themselves. The speakers at this event noted that Indigenous people are not fighting for themselves, but for the generations to come. I learned it is important to raise children with a connection to their culture and a connection to their ancestors. It was humbling to be a part of the celebration and an observer of the healing process. At the end of the healing ceremony we said a prayer for those at Standing Rock who are protesting the oil pipeline and putting their life on the line for their people.

The next event I attending was called "Healthy Relationships: An Indigenous Workshop." Jillene Joseph, from the Native Wellness Institute, and the FGC hosted this event. The workshop was filled with people; we all sat on chairs in a large circle inside the Native American Student and Community Center building at Portland State University. We began with some get-to-know-you games and eventually broke out into smaller groups to begin the workshop. During this event I learned more about the four components that make up the circle of wellness: physical, mental, emotional, and spiritual aspects. Jillene explained that balance between each of these four quadrants is important for overall health and healing. She said that unhealthy relationships often develop when one of the quadrants is out of balance. During this workshop we also talked about historical and intergenerational trauma. We wrote down examples of historical trauma, because as Jillene mentioned, it is important for AI/ANs to understand what it is they must overcome in order to move forward. Jillene talked about how the abuse that occurred in the residential boarding schools changed the way that the brain functions. She explained that our frontal cortex allows us to process potential consequences to our actions, but when people endure trauma the midbrain becomes more activated in decision making, which can cause people to make decisions that may not be in their best interest. We also talked about how the United States government perpetrated genocidal tactics against Indigenous peoples and 


\section{CULTURALLY RESPONSIVE DIABETES INTERVENTIONS}

to this day do not fully acknowledge this fact. Some tribes no longer exist today because of settlers and colonial practices. Jillene said that the United States government does not want to talk about historical trauma because they do not want to talk about healing.

During the next activity we filled out a "trauma web." On the left hand side of the page there was a list of traumatic events. On the right hand side of the page there was a list of unhealthy behaviors. The center of the page read the word "you." We were instructed to draw a line from each of the traumatic events that we have experienced to the center of the page and then to draw a line from the center of the page to each of the unhealthy behaviors that we exhibit. Jillene explained that unhealthy behaviors are a result of trauma. She said that the answer to trauma is healing and that we should be bringing healing energy to our relationships. We learned that healing is a journey, not a destination. Jillene then had us draw a circle around each side of the trauma web so it formed the shape of a butterfly. She explained that butterflies represent growth.

After we broke out into smaller groups, Jillene had us think of ways in which we heal ourselves. One person in my group said that she healed when she learned her spiritual name. She said she is a "mixed blood" or half white, half AI. She said having a spiritual name helped her find her purpose in life. Another person in my group said that she listens to her ancestors when she finds herself in difficult situations.

Two of the speakers at this event are group fitness instructors on their reservation. They explained that it is important for people to stay healthy and well not just for themselves, but for their culture and community too. The exercise class that they instruct is not just about fitness, but about connecting with the earth. They teach a class called "Earth Jam" that incorporates elements of the earth to form a holistic workout program. One of the speakers wanted to emphasize that 


\section{CULTURALLY RESPONSIVE DIABETES INTERVENTIONS}

although AI/AN nations have high rates of disease, they also have innovative health knowledge that comes from their people.

\section{Discussion}

In the following section I will synthesize culturally responsive diabetes interventions within the context of AI/AN health and determine the role of history, culture, and resilience in shaping these practices and approaches.

Some of the main elements of AI/AN health and healing include, tribal sovereignty, connecting to culture and the land, education on historical/ intergenerational trauma, engaging with the community, and focusing on resilience. The understanding of history is crucial when it comes to AI/AN health. The extent of historical trauma endured by AI/ANs is devastating. The health disparities experienced by AI/AN populations today are predominantly due to a history of forced removal, genocidal tactics, and detrimental environmental policies. It is of utmost importance that health professionals who wish to serve this population understand and fully appreciate the significance of this history. Considering the impact of displacement from ancestral lands on diabetes, those who are displaced to reservation lands are reliant on government food assistance programs that serve low quality, canned food (Jernigan, Salvatore, Styne, \& Winkleby, 2011). It is also common for those living on a reservation to be in areas isolated and removed, with the closest grocery store two hours or more away (Mitchell, 2012) and due to high poverty rates in reservation communities, people may be unable to drive these distances if they do not own a car, have money for gas, or simply do not have the time due to childcare or other family obligations (Jernigan, Salvatore, Styne, \& Winkleby, 2011). Health interventions must recognize these determinants of health using the CBPR principles. 


\section{CULTURALLY RESPONSIVE DIABETES INTERVENTIONS}

When it comes to culturally responsive care, the community must be involved in every step of the research process. CBPR recognizes the value of tribal knowledge and respects selfdetermination. AIs honor the wisdom of the Elders and experience should be respected just as academic degrees are (NCAI, 2012). Additionally, self-determination plays a large role in health and healing and sometimes well-intended health professionals may get in the way of this process. This is one reason why it is important to challenge one's worldview with education and time in the community. It is most productive to ask the community what they need and serve as a resource instead of assuming what is best and wanted (NCAI, 2012). This concept was highlighted both in the published literature and by people from the events that I attended. Many academic journals suggest that CBPR should be taught at the core competency for all incoming health professionals (Wallerstein \& Duran, 2006).

In addition to CBPR, connecting to cultural practices is a fundamental part of healing. Research has shown that incorporating cultural practices into healing techniques can mitigate negative health outcomes that stem from trauma (Walters \& Simoni, 2002). AI/ANs have a holistic view of health and healing that incorporates physical, mental, emotional, and spiritual aspects (Mitchell, 2012). These four aspects make up the circle of wellness and each quadrant must be in balance with one another to ensure good health. This concept was presented during the wellness events that I attended and was a useful way to visualize good health. Storytelling is another example of a traditional practice that is used in intervention strategies to identify upstream determinants of health (Jerigan et al., 2015). The use of digital storytelling discussed in the CBPR example, proved to be very effective at identifying barriers to healthy and culturally appropriate foods, and policies were implemented as a result to help eliminate some of these barriers. Traditional foods should be used as a means of improving health, as these are the foods 


\section{CULTURALLY RESPONSIVE DIABETES INTERVENTIONS}

that connect people to their ancestors and nourish both the body and the soul (Mitchell, 2012).

Community gardens that grow traditional foods are one way for people to connect to the land and have increased access to healthy food. In this setting, people can learn about the foods they harvest as well as about the cultural practices that have guided their ancestors for centuries. The thoughtful preparation and serving of food is a major component of good health (Newberry, 2013). AI/ANs have a deep relationship with food and nourishing the spirit is vital to creating long-lasting health (Newberry, 2013). Hunting and gathering are traditional forms of exercise that typically expend a lot of energy (Earle, 2011). "Earth Jam" is an example of a holistic, culturally appropriate workout routine.

The events that I attended reinforced the information I read about in the published literature. For example, when I was at the Healthy Relationships workshop one person said that they healed when they learned their spiritual name. Another person said they would look to their ancestors for advice on what to do in certain situations. Many people also said that they heal through ceremony, songs, and dances. One of the speaker from the "Indigenous Healing and Celebration" event said that she healed once she was able to connect to her culture. The “indigenist stress coping model” emphasizes that cultural practices can buffer the effects of negative health outcomes in response to stress. This shows that culture is a fundamental part of health and healing. I learned that many AI/ANs are interested in exploring historical and intergenerational trauma as a means of understanding potential challenges in contemporary life situations and ways to overcome them. AI/AN have endured a long history of trauma and maltreatment from the United States Government as a result of colonization, but the answer to healing is inherent within AI/AN culture and ways of life. 


\section{CULTURALLY RESPONSIVE DIABETES INTERVENTIONS}

\section{Conclusion}

Since I began this project in Fall 2016, I have watched my perspectives and worldviews begin to shift. One of the main points that I took away from this project is how profound Indigenous ways of knowing are. Overall, AI/AN have a holistic view of health and healing that incorporates the whole person and environmental factors. Western medicine is often very symptoms based and will only work on treating the symptoms as opposed to addressing the root cause of health conditions. AI/AN health is complex and it is important for health practitioners to know why this is. Additionally, each nation is very diverse and may require different methods of healing. I am thankful for the learning opportunity that this project presented and would like to continue exploring these topics more with my newly found outlook on life. 


\section{CULTURALLY RESPONSIVE DIABETES INTERVENTIONS}

\section{References}

Health Share of Oregon. (n.d.). Retrieved May 18, 2017, from

http://www.healthshareoregon.org/transforming-health-together/community-

health/creating-a-healthy-community/future-generations-collaborative

U.S. Public Health Service Syphilis Study at Tuskegee. (2013, December 30). Retrieved May 18, 2017, from https://www.cdc.gov/tuskegee/

Auerhahn, N., \& Laub, D. (1998). Intergenerational memory of the Holocaust. In Y. Danieli (Ed), International handbook of multigenerational legacies of trauma (pp. 341-354). New York: Plenum.

Barnes, P. M., Adams, P. F., \& Powell-Griner, E. (2010, March 9). Health Characteristics of the American Indian or Alaska Native Adult Population: United States, 2004-2008(Rep. No. 20). Retrieved April 17, 2017, from Centers for Disease Control and Prevention website: https://www.cdc.gov/nchs/data/nhsr/nhsr020.pdf

Blakeley, J., \& Park, J. K. (2004). Broken Promises: Evaluating the Native American Health Care System (Rep.). Washington D.C, MD: U.S Commission on Civil Rights.

Boomersbach, J. (2008, November). Arizona's Broken Arrow: Did Arizona State University Genetically Rape the Havasupai Tribe? Retrieved February 16, 2017, from 


\section{CULTURALLY RESPONSIVE DIABETES INTERVENTIONS}

http://janabommersbach.com/arizonas-broken-arrow-did-arizona-state-universitygenetically-rape-the-havasupai-tribe/

Canada's residential schools: The Inuit and Northern Experience(Vol. 2). (2015). Monteal: McGill-Queen's University Press.

Commission on Social Determinants of Health. (2007, April 30). Social determinants and Indigenous health: The International experience and its policy implications. (Rep.). Retrieved May 23, 2017, from Commission on Social Determinants of Health website: http://www.who.int/social_determinants/resources/indigenous_health_adelaide_report_07 .pdf

Compher, C. (2006). The Nutrition Transition in American Indians. Journal of Transcultural Nursing,17(3), 217-223. doi:10.1177/1043659606288376

Cooper, L. A., Ortega, A. N., Ammerman, A. S., Buchwald, D., Paskett, E. D., Powell, L. H., .. . Williams, D. R. (2015). Calling for a Bold New Vision of Health Disparities Intervention Research. Am J Public Health American Journal of Public Health, 105(S3), 374-376. doi:10.2105/ajph.2014.302386

Crosby, A. W. (1976). Virgin Soil Epidemics as a Factor in the Aboriginal Depopulation in America. The William and Mary Quarterly,33(2), 289. doi:10.2307/1922166 


\section{CULTURALLY RESPONSIVE DIABETES INTERVENTIONS}

Czyzewski, K. (2011, May 16). Colonialism as a Broader Social Determinant of Health. IIPJ International Indigenous Policy Journal, 2(1). doi:10.18584/iipj.2011.2.1.5

Debruyn, L., \& Brave Heart, M. Y. (1998). The American Indian Holocaust: Healing Historical Unresolved Grief. American Indian and Alaska Native Mental Health Research,8(2), 6082. doi:10.5820/aian.0802.1998.60

Dillingham, B. (1977). Sterilization of Native Americans. American Indian Journal. Retrieved May 21, 2017, from https://eric.ed.gov/?id=EJ162861.

Disparities. (n.d.). Retrieved April 17, 2017, from https://www.healthypeople.gov/2020/about/foundation-health-measures/Disparities

Drabiak-Syed, Katherine (2010) Lessons from Havasupai Tribe v. Arizona State University Board of Regents: Recognizing Group, Cultural, and Dignitary Harms as Legitimate Risks Warranting Integration into Research Practice. Journal of Health \& Biomedical Law, 6 (2). pp. 175-226.

Dunbar-Ortiz, R. (2014). An Indigenous Peoples' History of the United States. Boston, MA: Beacon Press. 


\section{CULTURALLY RESPONSIVE DIABETES INTERVENTIONS}

Earle, L. (2011). Traditional and Aboriginal Diets in Health Retrieved November 3, 2016, from http://www.nccah-ccnsa.ca/docs/social determinates/1828_NCCAH_mini_diets_health_final.pdf

Elias, B., Mignone, J., Hall, M., Hong, S. P., Hart, L., \& Sareen, J. (2012). Trauma and suicide behaviour histories among a Canadian indigenous population: An empirical exploration of the potential role of Canada's residential school system. Social Science \& Medicine,74(10), 1560-1569. doi:10.1016/j.socscimed.2012.01.026

Evans-Campbell, T. (2008). Historical Trauma in American Indian/Native Alaska Communities: A Multilevel Framework for Exploring Impacts on Individuals, Families, and Communities. Journal of Interpersonal Violence, 23(3), 316-338.

doi:10.1177/0886260507312290

Evans-Campbell, T., \& Walters, K. L. (2006). Indigenist practice competencies in child welfare practice: A decolonization framework to address family violence and substance abuse among First Nations peoples. In R. Fong, R. McRoy, \& C. Ortiz Hendricks, (Ed.), Intersecting child welfare, substance abuse, and family violence: Culturally competent approaches (pp. 266-290). Washington, DC: CSWE Press.

Flanigan, P. (Writer). (2015, August 19). Trauma and 'Blood Memory'[Radio broadcast]. In Think Out Loud. Oregon: OPB. 


\section{CULTURALLY RESPONSIVE DIABETES INTERVENTIONS}

Garrison, N. A., \& Cho, M. K. (2013, October 1). Awareness and Acceptable Practices: IRB and Researcher Reflections on the Havasupai Lawsuit. AJOB Primary Research, 4(4), 55-63. doi:10.1080/21507716.2013.770104

Grivetti, L. E., \& Ogle, B. M. (2000). Value of traditional foods in meeting macro- and micronutrient needs: the wild plant connection. Nutrition Research Reviews, 13(01), 31. doi:10.1079/095442200108728990

Gubrium, A. (2009). Digital Storytelling: An Emergent Method for Health Promotion Research and Practice. Health Promotion Practice,10(2), 186-191.

doi: $10.1177 / 1524839909332600$

Harris, S., \& Harper, B. L. (2001). Lifestyles, Diets, and Native American Exposure Factors Related to Possible Lead Exposures and Toxicity. Environmental Research,86(2), 140148. doi:10.1006/enrs.2001.4250

Isham, J., Narayan, D., \& Pritchett, L. (1995). Does participation improve performances? Establishing causality with subjective data. World Bank Economic Review, 9(2), 175200.

Jaimes M. A., Halsey T. (1992). American Indian women: At the center of indigenous resistance in contemporary North American. In M. A. Jaimes (Ed.), The state of Native America: Genocide, colonization \& resistance. (pp. 311-344). Boston: South End Press. 


\section{CULTURALLY RESPONSIVE DIABETES INTERVENTIONS}

Jernigan, V. B., Peercy, M., Branam, D., Saunkeah, B., Wharton, D., Winkleby, M., . Buchwald, D. (2015). Beyond Health Equity: Achieving Wellness Within American Indian and Alaska Native Communities. Am J Public Health American Journal of Public Health, 105(S3). doi:10.2105/ajph.2014.302447

Jernigan, V. B., Salvatore, A. L., Styne, D. M., \& Winkleby, M. (2011, September 1). Addressing food insecurity in a Native American reservation using community-based participatory research. Health Education Research, 27(4), 645-655. doi:10.1093/her/cyr089

Kauffman J. A., Joseph-Fox Y. K. (1996). American Indian and Alaska Native women. In M. Bayne-Smith (Ed.), Race, Gender, and Health (pp. 68-93). Thousand Oaks, CA: Sage Publications.

Kennedy, M. (2015, December 15). Attitudes of 'coldness, indifference' behind thousands of residential school deaths: TRC report. Retrieved May 04, 2017, from http://news.nationalpost.com/news/canada/attitudes-of-coldness-indifference-behind$\underline{\text { thousands-of-residential-school-deaths-trc-report }}$

Lawrence, J. (2000). The Indian Health Service and the Sterilization of Native American Women. The American Indian Quarterly, 24(3), 400-419. doi:10.1353/aiq.2000.0008 


\section{CULTURALLY RESPONSIVE DIABETES INTERVENTIONS}

Leadership for Healthy Communities. (2010, May). Overweight and Obesity Among American Indian and Alaska Native Youths. Retrieved November 3, 2016, from https://folio.iupui.edu/bitstream/handle/10244/823/20100512lhcamerindian.pdf;sequence $=1$

Lloyd-Jones, D. M., Hong, Y., Labarthe, D., Mozaffarian, D., Appel, L. J., Horn, L. V., . . . Rosamond, W. D. (2010). Defining and Setting National Goals for Cardiovascular Health Promotion and Disease Reduction: The American Heart Association's Strategic Impact Goal Through 2020 and Beyond. Circulation,121(4), 586-613. doi:10.1161/circulationaha.109.192703

Minkler, M., \& Wallerstein, N. (Eds.). (2003). Community based participatory research in health. San Francisco: Jossey-Bass.

Mitchell, F. M. (2012). Reframing diabetes in American Indian communities: A social determinants of health perspective. Retrieved November 03, 2016, from http://www.ncbi.nlm.nih.gov/pubmed/23029974

Mullan, F. (1989). Plagues and politics: the story of the United States Public Health Service. New York: Basic Books.

Narayan, D. (1992). The contribution of people's participation to rural water supply: Findings from 122 projects. Washington, DC: World Bank. 
CULTURALLY RESPONSIVE DIABETES INTERVENTIONS

NCAI Policy Research Center and MSU Center for Native Health Partnerships. (2012). 'Walk softly and listen carefully': Building research relationships with tribal communities. Washington, DC, and Bozeman, MT: Authors.

Newberry, K. (2013). Powerful Medicine: A Garden Gives Portland's Native Community a Place to Call Home. Retrieved February 12, 2017, from http://www.kerrynewberry.com/portfolio-item/powerful-medicine-a-garden-givesportlands-native-community-a-place-to-call-home/

Pacheco, C. M., Daley, S. M., Brown, T., Filippi, M., Greiner, K. A., \& Daley, C. M. (2013, December). Moving Forward: Breaking the Cycle of Mistrust Between American Indians and Researchers. American Journal of Public Health, 103(12), 2152-2159. doi:10.2105/ajph.2013.301480

Petit, C. (1998, February 19). Trying to Study Tribes While Respecting Their Cultures / Hopi Indian geneticist can see both sides. Retrieved February 16, 2017, from http://www.sfgate.com/news/article/Trying-to-Study-Tribes-While-Respecting-Their3012825.php

Redwood, D. G., Ferucci, E. D., Schumacher, M. C., Johnson, J. S., Lanier, A. P., Helzer, L. J., . .. Slattery, M. L. (2008). Traditional foods and physical activity patterns and associations 


\section{CULTURALLY RESPONSIVE DIABETES INTERVENTIONS}

with cultural factors in a diverse Alaska Native population. International Journal of Circumpolar Health,67(4), 335-348. doi:10.3402/ijch.v67i4.18346

Rhoades, E. R., \& Rhoades, D. A. (2014). Public Health Then and Now. American Journal of Public Health, 104(S3), 278-285.

Roubideaux, Y. (2002, September). Perspectives on American Indian Health. American Journal of Public Health, 92(9), 1401-1403.

Rubin, P. (2004, May 27). Indian Givers. Retrieved February 16, 2017, from http://www.phoenixnewtimes.com/news/indian-givers-6428347

Santos, L. (2008). Genetic Research in Native Communities. Progress in Community Health Partnerships: Research, Education, and Action,2(4), 321-327. doi:10.1353/cpr.0.0046

Simopoulos, A. P. (2008). The Importance of the Omega-6/Omega-3 Fatty Acid Ratio in Cardiovascular Disease and Other Chronic Diseases. Experimental Biology and Medicine,233(6), 674-688. doi:10.3181/0711-mr-311

Smith, A. (2005). Sexual violence as a tool of genocide. In Conquest: Sexual Violence and American Indian Genocide (pp. 7-33) Cambridge: South End Press. 


\section{CULTURALLY RESPONSIVE DIABETES INTERVENTIONS}

Straus, A. T., \& Delgado, L. (1996). Education for Extinction: American Indians and the Boarding School Experience, 1875-1928. David Wallace Adams. American Journal of Education, 104(4), 328-334. doi:10.1086/444140

The World Health Report: Reducing Risks, Promoting Healthy Life(Rep.). (2002). Retrieved May 23, 2017, from The World Health Organization website: http://www.who.int/whr/2002/en/whr02_en.pdf?ua=1

Ubelaker, D. H., \& Dobyns, H. F. (1984). Their Number Become Thinned: Native American Population Dynamics in Eastern North America. Ethnohistory,31(4), 303. doi: $10.2307 / 482717$

Wallerstein, N. B., \& Duran, B. (2006, June 13). Using Community-Based Participatory Research to Address Health Disparities. Health Promotion Practice, 7(3), 312-323. doi:10.1177/1524839906289376

Walters, K. L. (1999). Urban American Indian Identity Attitudes and Acculturation Styles. Journal of Human Behavior in the Social Environment,2(1-2), 163-178. doi:10.1300/j137v02n01_11

Walters, K. L., \& Simoni, J. M. (2002, April). Reconceptualizing Native Women's Health: An “Indigenist” Stress-Coping Model. American Journal of Public Health, 92(4), 520-524. doi:10.2105/ajph.92.4.520 


\section{CULTURALLY RESPONSIVE DIABETES INTERVENTIONS}

Warne, D. (2006). Research and Educational Approaches to Reducing Health Disparities Among American Indians and Alaska Natives. Journal of Transcultural Nursing,17(3), 266-271. doi:10.1177/1043659606288381

Wesley-Esquimaux, C. (2007). Inside Looking Out, Outside Lookng In. First Peoples Child \& Family Review,3. Retrieved January 14, 2017, from http://journals.sfu.ca/fpcfr/index.php/FPCFR/article/viewFile/61/99 